\section{Transfer shift performance of first-grade children as a function of presentation locus of relevant cues}

\author{
THOMAS F. CUNNINGHAM \\ St. Lawrence University, Canton, N.Y. 13617 \\ KARL THALLER \\ State University of New York, College at Potsdam, Potsdam, N.Y. 13676 \\ and \\ CAROL CAMPBELL
}

St. Lawrence University, Canton, N.Y. 13617

Forty children from first-grade classes learned a two-choice visual discrimination problem and a subsequent shift problem in which the presentation locus of relevant cues was varied. There was no difference in original learning due to relevant cue-presentation area. Shift performance was affected adversely by a switch in the relevant area of cue presentation. The results were interpreted in terms of the attention theory of Zeaman \& House (1963).

The physical locus of stimuli in visual materials may be an important factor in determining the probability of attending to the relevant cues of a learning problem. Traditionally, figure and ground have been used as terms to describe regions or areas of a visual field (Hebb, 1966; Koffka, 1928; Kohler, 1947; Rubin, 1915). The ability to perceive figure-ground relationships has been emphasized in the perception literature, but there is a paucity of research concerned with manipulating figure and ground as stimulus properties of visual material in learning situations. In the present study, figure and ground are identified as independent stimulus dimensions within which the relevant cues of discrimination problems are presented.

Research performed by Gollin (1964, 1965, 1966), Gollin \& Liss (1962), and Gollin \& Savoy (1968) has demonstrated that, in conditional discrimination problems, the stimulus characteristics of different backgrounds can determine the choice of appropriate figural stimuli in normal children between $3 \frac{1}{2}$ and 6 years. Anderson (1968), adopting the rationale of attention theory (Zeaman \& House, 1963), treated figure and ground as independent stimulus dimensions and found that retarded children with mental ages between 6 and 9 years learned color and texture discrimination problems equally well when the relevant cues were presented in the figure or ground areas. Although it appears that Anderson's Ss did not differ in the probability of attending to figure and ground dimensions, methodological deficiencies in the study make the results tenuous.

In the present study, normal children were given an original discrimination problem in which the are referred to as extradimensional shifts by Zeaman and House. SUBJECTS

The Ss were 40 experimentally naive children, 20 boys and 20 girls, enrolled in first-grade classes at the Banford Elementary School, Canton, N.Y. The mean age of the sample was 6 years, 8 months. Ss were assigned randomly to four experimental groups, with the provision that each group had an equal number of males and females. APPARATUS

The apparatus was an automated version of the Wisconsin General Test Apparatus. It consisted of a $19 \times 19$ in. front panel on which was located a $3^{1 / 4} \times 4^{1 / 2}$ in. stimulus screen. Two independently manipulable clear Plexiglas frames, each measuring $3^{1 / 4} \times 2^{1 / 4}$ in., covered the stimulus screen on which two stimulus pictures were presented via a Carousel projector mounted on the rear of the panel. Each Plexiglas frame covered a $2 \times 2$ in. picture and permitted an independent choice by an $S$ of the correct picture. The $\mathrm{S}$ was able to touch directly the picture he chose by pushing on one of the Plexiglas frames. A correct choice resulted in the brief onset of a red light above the stimulus screen and the simultaneous delivery of an $\mathrm{M} \& \mathrm{M}$ into a candy tray located below the stimulus screen.

There was a $1 / 4-i n$. separation between picture stimuli on the stimulus screen. For each picture, the size and form of the figure and ground areas were held constant. The figure area consisted of a square form, $1 \frac{1 / 4}{41 / 4} \mathrm{in}$., superimposed on a larger square form, the ground, which measured $2 \times 2$ in. The total visible area of the figure was $1.56 \mathrm{sq}$ in., and the visible ground area was $2.44 \mathrm{sq}$ in. The ratio of visible figure area to visible ground area was $1: 1 \frac{1 / 2}{2}$. This ratio was determined in previous research in which children in Elementary Grades 1 and 2 of the Potsdam College Campus School were asked to estimate subjectively areas of equal size in figure and ground drawings of square play areas. Two psychophysical procedures, the method of reproduction and absolute judgment, were used. There were no significant differences in the results obtained by these methods. In both cases, the subjectively judged equal size of ground and figure areas had a ratio of $1: 1 \frac{1 / 2}{2}$ the physical size. There was no significant difference in judgment according to sex. The ratio obtained by Thaller ${ }^{1}$ was used in the present study to avoid confounding the effect of presentation area and relative size of figure and ground areas. GENERAL PROCEDURE

Each $S$ was brought into the experimental room and told: "We are 
Table 1

Geometric Mean Errors and Transformed Variance Values on the Original and Shift Problems

\begin{tabular}{|c|c|c|c|c|c|}
\hline & \multirow[b]{2}{*}{ Groups } & \multicolumn{2}{|c|}{ Original Problem } & \multicolumn{2}{|c|}{ Shift Problem } \\
\hline & & $\begin{array}{l}\text { Mean } \\
\text { Errors }\end{array}$ & Variance & $\begin{array}{l}\text { Mean } \\
\text { Errors }\end{array}$ & Variance \\
\hline 1 & Figure-Figure & 2.704 & .952 & 2.838 & .119 \\
\hline 2 & Figure-Ground & 2.371 & 1.167 & 11.455 & .294 \\
\hline 3 & Ground-Ground & 2.529 & .963 & 1.750 & .067 \\
\hline 4 & Ground-Figure & 1.762 & .485 & 10.544 & .346 \\
\hline
\end{tabular}

going to play a candy game. You will see two pictures in this window at the same time. One of the pictures is the right answer to the game. Try to choose the right picture and push on the glass in front of it. If you are right, the red light will go on over the window and you will find an $M \& M$ in the small tray below the window. These you may keep and put in your bag. Try to do your best and learn which one is right as quickly as possible." In addition to the candy and light reinforcers, $E$ reinforced correct responses verbally with, "Good," and incorrect responses with, "No." A 6-sec intertrial interval was invoked automatically from the time $S$ made a response until the onset of a new slide. The original stimulus slide was not present during the 6-sec interval. A noncorrection procedure was used.

Prior to the initiation of experimental problems, each $\mathbf{S}$ was given a day of pretraining with two junk picture stimuli which had no distinctive figure and ground stimulus characteristics. The acquisition criterion for pretraining was the same as for later training problems, i.e., 20 correct responses out of 25 trials. A daily testing session was 25 trials throughout the experiment.

\section{ORIGINAL PROBLEM}

All Ss received training on an original color discrimination problem in which four color cues were used: red, green, white, and brown. Two of the four experimental groups were given a color problem in which red and green were the relevant cues in the figure and white and brown were the irrelevant color cues of the ground area. The remaining two groups were given the same relevant cues, red and green, in the ground area and the irrelevant cues of white and brown in the figure area. Red and green were counterbalanced as the positive cues across Ss in all groups. The irrelevant cues were varied randomly within trials with the provision that an irrelevant cue not occur in combination with a specific relevant cue on more than two successive trials. The position of the correct cue was randomized over trials according to a modified Gellermann (Fellows, 1967) series. The same procedure for the relevant and irrelevant cues was followed throughout the experiment.

During the original training, a special training procedure was used at the end of an initial block of eight trials in which an $S$ made five or fewer correct responses. The slides were advanced manually in succession for two trials. Without indicating the specific area of the picture or the positive cue, $E$ pointed to the two positive stimulus pictures over two trials and said, "This is the right picture. You can always get the $M \& M$ by pushing this picture." In each training trial, E pointed to the incorrect picture saying, "This is wrong. You never get the $M \& M$ by pushing this picture." This procedure is modeled after that used by Dickerson, Wagner, \& Campione (1970), and the rationale for its use has been presented by Dickerson (1967) and House \& Zeaman (1962). SHIFT PROBLEM

After original training, the $S s$ in all groups were given a shift problem which had two new relevant color cues, blue and yellow, and two new irrelevant color cues, black and orange. As in original training, each relevant cue appeared equally often as the positive cue across Ss within groups. The general procedure was the same as for the original problem, except that the special training was omitted. Transition from the original problem to the shift problem was separated by a 24-h period for all Ss and instituted without comment by $\mathrm{E}$. All Ss were given 100 trials or 4 days of training in which to reach criterion.

The four experimental groups are labeled according to the area of presentation of the relevant cues in the original problem and the relevant area of cue presentation in the shift problem. The figure-figure group was given original training with the positive color cue of red or green in the figure area and then given an ID shift with blue or yellow appearing as the positive cue in the figure area. The figure-ground group was given the relevant cues of red and green in the figure area of the original problem and then shifted to a color problem in which the relevant cues of blue and yellow appeared in the ground area. A similar procedure was followed for the remaining two groups, i.e., the ground-ground group and the ground-figure group.

\section{RESULTS}

The performance measure used was the number of errors through criterion. For Ss failing to attain criterion on the shift problem, the number of errors in 100 trials was the score assigned. A logarithmic $(\mathrm{X}+1)$ transformation was employed to correct for heterogeneity of variance. The geometric mean errors and tranformed variance values for each group in the original learning and shift problem is presented in Table 1 . The scores on the original and shift problems are not comparable, since all Ss reached criterion on the original problem while some $S$ s did not attain criterion on the shift problem.

The original problem was learned quickly by all Ss, with 35 out of $40 \mathrm{Ss}$ solving the problem in three errors or less, and required no special training. Five Ss required special training, four in the figure-relevant condition and one in the ground-relevant condition. The geometric mean errors presented in Table 1 indicate that performance was highly similar for the figure-relevant groups ( 1 and 2 ) and the ground-relevant groups ( 3 and 4 ). A one-way analysis of variance of the data for $16 \mathrm{Ss}$ in the figure-relevant condition and 19 Ss in the ground-relevant condition indicated no difference in difficulty level of the original problem as a function of relevant presentation locus, $F<.5$, $\mathrm{df}=1 / 33$. The inclusion of error data from the $S$ s requiring special training did not alter the outcome, $F<.7$, $\mathrm{df}=1 / 38$. With all Ss considered, there was no consistent difference in performance attributable to sex, $F<.5, \mathrm{df}=1 / 39$

A 2 by 2 factorial analysis of variance was used to analyze performance in the shift problem. The two factors and their levels were: (1) area of relevant cue presentation in the original problem, figure, or ground, and (2) shift presentation area of the relevant cues, figure, or ground. There were no significant main effects due to the presentation locus of the original problem $(F<1)$ or shift problem $(F<1)$. There was, however, a significant interaction between original presentation locus and shift locus, $\mathrm{F}=20, \quad \mathrm{df}=1 / 36, \quad \mathrm{p}<.001$. Duncan's new multiple-range test (Steel \& Torrie, 1960) was used to compare differences among treatment means. The performance of the figure-figure and ground-ground groups was consistently superior $(p<.01)$ to the performance of the figure-ground and ground-figure groups. There was no significant difference $(p>.05)$ in performance between figure-figure and ground-ground groups or between 
figure-ground and ground-figure groups. As in original training, the sex variable did not prove significant, $\mathrm{F}<.5$.

\section{DISCUSSION}

The results of the present study did not indicate a significant difference in performance during original learning when the relevant cues were presented in figure or ground areas. This finding is interpreted as indicating that normal children of approximately $6 \frac{1 / 2}{2}$ years are capable of attending to figure or ground dimensions of stimuli. The present findings extend the generality of Anderson's (1968) study in which retarded children of the same approximate mental age as the chronological age of the $S s$ in the present study learned figure-relevant and ground-relevant problems with equal facility.

Performance in the shift problems confirmed the predictions derived from attention theory. The figure-figure and ground-ground groups performed significantly faster than the figure-ground and ground-figure groups. The median untransformed number of errors was 1 for the former groups and 12 for the latter groups. The maintenance of the original relevant presentation dimension in the shift problem resulted in superior performance in comparison to a shift of the original relevant dimension from figure to ground or ground to figure. The use of the same relevant presentation dimension across problems is referred to as a type of intradimensional shift. The transfer paradigm in which the original presentation dimension is changed in a subsequent problem is identified as a type of extradimensional shift.

\section{REFERENCES}

ANDERSON, V. H. Figure and ground as attentional components in the discrimination learning of retardates. Unpublished doctoral dissertation, Oklahoma State University, 1968.

DICKERSON, D. J. Irrelevant stimulus dimensions and dimensional transfer in the discrimination learning of children. Journal of Experimental Child Psychology, 1967, 5, 228-236.

DICKERSON, D. J., WAGNER, J. F. \& CAMPIONE, J Discrimination shift performance of kindergarten children as a function of variation of the irrelevant shift dimension. Developmental Psychology, 1970, 3, 229-235.

FELLOWS, B. J. Chance stimulus sequences for discrimination tasks. Psychological Bulletin, 1967, 67, 87-92.

GOLLIN, E. S. Reversal learning and conditional discrimination in children. Journal of Comparative \& Physiological Psychology, 1964, 58, 441-445.

GOLLIN, E. S. Factors affecting conditional discrimination in children. Jourmal of Comparative \& Physiological Psychology, $1965,60,422-427$.

GOLLIN, E. S. Solution of conditional discrimination problems in young children. Journal of Comparative \& Physiological Psychology, 1966, 62, 454-456.

GOLLIN, E. S., \& LISS, P Conditional discrimination in children. Journal of Comparative \& Physiological Psychology, $1962,55,850-855$

GOLLIN, E. S., \& SAVOY, P. Fading procedures and conditional discrimination in children. Joumal of the Experimental Analysis of Behavior, 1968 . 11, 443-451.

HEBB, D. D. A textbook of psychology. Philadelphia: Saunders, 1966.

HOUSE, B. J., \& ZEAMAN, D. Reversal and nonreversal shifts in discrimination learning of retardates. Journal of Experimental Psychology, 1962, 63, 444-451.

KOFFKA, K. The growth of the mind. New York: Harcourt, Brace, 1928.

KOHLER, W. Gestalt psychology. New York: Liveright, 1947

RUBIN, E. Figure and ground. In D. C. Beardslee and $M$. Wertheimer (Eds.) Readings in perception. Princeton, N.J: Van Nostrand, 1958

STEEL, R. G., \& TORRIE, J. H. Principles and procedures of statistics. New York: McGraw-Hill, 1960.

ZEAMAN, D. \& HOUSE, B. J, The role of attention in retardate discrimination learning. In N. R. Ellis (Ed.), Handbook of mental deficiency. New York: McGraw-Hill, 1963

1. Thaller, K. Subjective equality of ground figure areas in young children. Unpublished paper, 1970.

\section{CURRENT LITERATURE ON PERFORMANCE}

ADAMS, R. M. (Fort Hays Kansas State College, Hays, Kans. 67601). Number as a stimulus in a card-sorting task. Psychonomic Science, 1971, 23, 183-184.

BERGER, R. J. (Division of Natural Sciences I, University of California, Santa Cruz, Calif. 95060), WALKER, J. M., SCOTT, T. D., MAGNUSON, L. J., \& POLLACK, S. L. Diurnal and nocturnal sleep stage patterns following sleep deprivation. Psychonomic Science, 1971, 23, 273-275.

BERMAN, P. W. (Pennsylvania State University, University Park, Pa. 16802), \& MYERS, J. Effects of ratio of win-stay to lose-shift problems on children's performance on win-stay problems. Psychonomic Science, 1971, 23, 131-132.

BOYER, W. N. (Colorado State University, Fort Collins, Colo. 80521), BULLOCK, M., \& VINEY, W. Effect of stimulus variation upon reversal shift performance of kindergarten children. Psychonomic Science, 1971, 23, 166-167.

BROOKSHIRE, R. H. (Veterans Administration Hospital, Minneapolis, Minn. 55417). Response suppression by response-contingent noise: Effects of conditioning history.
Psychonomic Science, 1971, 23, 265-267.

DeROSA, D. V. (Bowling Green State University, Bowling Green, Ohio 43403), \& BECKWITH, M. Retrieval of information from organized memory sets. Psychonomic Science, 1971, 23, 177-179.

HALPIN, S. M. (U.S. Army Research Institute of Environmental Medicine, Natick, Mass. 01760), STREUFERT, S., STEFFEY, J., \& LANHAM, $N$. Information load, proportion of relevance, and relevance perception. Psychonomic Science, 1971, 23, 404-406.

HARRIS, L. (Michigan State University, East Lansing, Mich. 48823), \& ALLEN, T. The effects of stimulus alignment on children's performance in a conservation of length problem. Psychonomic Science, 1971, 23, 137-139.

HUGHES, W. G. (College of William and Mary, Williamsburg, Va. 23185), \& SHEAN, G. D. Ability to control GSR amplitude. Psychonomic Science, 1971, 23, 309-311.

MARTUZA, V. R. (University of Delaware, Newark, Del. 19711). The effects of experimenter expectancy on guessing performance and level of confidence in guessing accuracy. Psychonomic Science, 1971, 23, 169-170.

MORRIS, C. J. (Denison University, Granville, Ohio 43023). Electroencephalographic and evoked potential correlates of reaction time and visual discrimination performance. Psychonomic Science, 1971, 23, 193-195.

SEYMOUR, P. H. K. (The University, Dundee, Scotland). Effects of repetition of display components on the latency of multiple reports of congruence. Quarterly Journal of Experimental Psychology, 1971, 23, 82-96.

THACKRAY, R. I. (Civil Aeromedical Institute, FAA, Oklahoma City, Okla. 73125), \& JONES, K. N. Level of arousal during Stroop performance: Effects of speed stress and "distraction." Psychonomic Science, 1971, 23, 133-135.

WHITMAN, C. P., \& GELLER, E. S. (Virginia Polytechnic Institute and State University, Blacksburg, Va. 24061). Runs of correct and incorrect predictions as determinants of choice reaction time. Psychonomic Science, 1971, $23,421-423$ 